\title{
Progress in treatment and outcome for children with neonatal haemochromatosis
}

\author{
D M Flynn, N Mohan, P McKiernan, S Beath, J Buckels, D Mayer, D A Kelly
}

See end of article for authors' affiliations

Correspondence to Dr Flynn, 3rd Floor,

Clinical Research Block,

Queen Elizabeth Hospital

Edgbaston, Birmingham

B15 2TH, UK;

flynndiana@hotmail.com

Accepted 28 July 2002

\begin{abstract}
Aim: To evaluate the role of antioxidant treatment and liver transplantation in the management of neonatal haemochromatosis.

Methods: A retrospective review was performed of eight infants with acute liver failure and raised ferritin levels between 1990 and 1998. From 1994, treatment with an antioxidant cocktail (vitamin E, $\mathrm{N}$-acetylcysteine, selenium, prostaglandin El, and desferrioxamine) was begun once the diagnosis was suspected. Pathological and other findings were reviewed, and outcome before and after antioxidant treatment was evaluated.

Results: Median age at presentation was 4 days with median ferritin levels of $4180 \mu \mathrm{g} / \mathrm{l}$ (range 1650-40 $000 \mu \mathrm{g} / \mathrm{l}$; normal range 110-503 $\mathrm{\mu g} / \mathrm{l})$. Three infants presented before 1994. One infant died before liver transplantation from acute liver failure and one from neurological damage after transplantation. The third patient underwent successful transplantation at day 13 and remains well on follow up 8 years later. From 1994, five patients received antioxidant treatment, of whom two responded: both responders started antioxidants earlier (by day 5) than non-responders and had lower peak ferritin levels (<4200 $\mathrm{gg} / \mathrm{l})$ and a milder phenotype. Treatment was continued until ferritin levels were $<500 \mu \mathrm{g} / \mathrm{l}$. Both children remain well with mean follow up of 42 months, with no recurrence of iron overload. One child showed a partial response to treatment and survived long enough for a liver transplant, but died from graft failure after the transplant. Two children did not respond to antioxidant treatment; both had multiorgan failure and were not listed for transplantation. Only three of the eight patients survived $(37.5 \%)$ over this time period.

Conclusion: Neonatal haemochromatosis can be a fatal disease with $>60 \%$ mortality. Early treatment with antioxidant cocktail is beneficial and may be curative in those who present with milder phenotype. Liver transplantation should always be considered at an early stage in non-responders and in children with more severe acute liver failure.
\end{abstract}

$\mathrm{N}$ eonatal haemochromatosis $(\mathrm{NH})$ is a rare perinatal disorder defined as severe liver disease associated with intrahepatic and extrahepatic siderosis presenting in utero or early in the neonatal period. ${ }^{1}$ The cause remains obscure, but it may develop secondary to abnormal fetoplacental iron handling or perinatal liver disease, or be familial. $^{1-3}$ There is an association with maternal lupus antibodies ${ }^{45}$ and with abnormal bile acid production. ${ }^{67}$ All infants present with acute liver failure with both intrahepatic and extrahepatic siderosis, which affects the parenchyma of the liver, pancreas, oral mucosa, and thyroid among other sites, but spares the reticuloendothelial system. ${ }^{1}$

Untreated, the disorder is almost uniformly fatal, but liver transplantation has been performed with some success, ${ }^{8-10}$ and from 1993 the use of an antioxidant cocktail has been suggested with initial reports of improved outcome. ${ }^{11}$

A retrospective review of all patients with neonatal haemochromatosis presenting between 1990 and 1998 to a national centre was performed to evaluate the role of an antioxidant cocktail and orthotopic liver transplantation in the management of the disease.

\section{METHODS}

A retrospective review of case notes and pathology results of infants referred to the Liver Unit at Birmingham Childrens' Hospital between 1990 and 1998 was performed. Eight children had a diagnosis of NH. The histology slides, pathology reports, and biochemical results of these patients were reviewed. The diagnosis of $\mathrm{NH}$ was based on the combination of acute liver failure, raised ferritin concentration (>1000 $\mu \mathrm{g} / \mathrm{l})$, increased intrahepatic iron with grade 4 hepatocyte siderosis that spared the reticuloendothelial system, and, where possible, evidence of extrahepatic siderosis. Other causes of liver disease including viral hepatitis, $\alpha_{1}$ antitrypsin deficiency, tyrosinaemia type I, galactosaemia, Zellweger's syndrome, and mitochondrial disorders were excluded. From 1994, abnormalities of bile acids were sought and excluded.

All patients received standard supportive treatment for acute liver failure and were considered for liver transplantation. Those presenting from 1994 were also treated with an antioxidant cocktail (table 1), which was continued until ferritin levels fell below $500 \mu \mathrm{g} / \mathrm{l}$ or death or liver transplantation occurred.

\section{RESULTS}

Eight infants (four boys, four girls) presented during 1990-1998 (table 2). Median gestational age was 40 weeks (range 35-40), and median birth weight 3200 g (range 27203780). Median age at presentation at Birmingham Childrens' Hospital was 4 days (range 0-31) with raised ferritin levels (median $4180 \mu \mathrm{g} / \mathrm{l}$; range 1650-40 $000 \mu \mathrm{g} / \mathrm{l}$; normal range $110-503 \mu \mathrm{g} / \mathrm{l}$ ) and prothrombin time (median 40 seconds, range 23-86 seconds). Serum iron concentration was raised (median $24.8 \mu \mathrm{mol} / \mathrm{l}$, range 3-68 $\mu \mathrm{mol} / \mathrm{l}$ ) (table 2 ).

Associated findings were noted in six of the eight patients. Two families were consanguineous (patients 1 and 5), one

Abbreviations: $\mathrm{NH}$, neonatal haemochromatosis; MRI, magnetic resonance imaging 
Table 1 Antioxidant treatment of infants with neonatal haemochromatosis

\begin{tabular}{ll}
\hline Antioxidant & Dose \\
\hline Desferrioxamine & $30 \mathrm{mg} / \mathrm{kg} /$ day iv \\
N-Acetylcysteine & $200 \mathrm{mg} / \mathrm{kg} /$ day iv \\
Selenium & $3 \mu \mathrm{kg} /$ day iv \\
Vitamin E & $25 \mathrm{IU} / \mathrm{kg} /$ day iv $/$ po \\
Prostaglandin E1 & $0.4-0.6 \mu g / \mathrm{kg} / \mathrm{hour}$ ivi \\
\hline
\end{tabular}

The dose of $\mathrm{N}$-acetylcysteine is gradually reduced after 24 hours. Prostaglandin infusion increased gradually over the first six to eight hours.

iv, Intravenous; po, by mouth; ivi,

with two previous perinatal deaths (patient 5). There were two affected siblings in one family in which the mother had positive autoantibodies to Ro and La (patients 3 and 7). Patients 4 and 8 had copresentation with sepsis, one with Coxsackie viral meningitis and the other with Escherichia coli septicaemia (table 2). Patients 1 and 2 presented late, but had been unwell for two weeks before admission. In all cases the pregnancy was normal and there was no maternal history of blood transfusion in any of the infants in this series.

$\mathrm{NH}$ was confirmed on histological examination of the liver biopsy specimen or at post mortem examination in seven patients. Characteristic histology was identified, with giant cell transformation and grade 3-4 siderosis in hepatocytes which spared Kupffer cells. Patient 1 had insufficient liver parenchyma remaining to be diagnostic, although there was evidence of iron deposition, and a diagnosis was made using this as supporting evidence to the clinical picture and raised ferritin concentration.

Patient 8 underwent magnetic resonance imaging (MRI) of the abdomen, which suggested extrahepatic iron deposition in the pancreas, and liver histology after 20 days of medical treatment was confirmatory. Patient 4 had supportive liver histology, but unfortunately the postmortem examination did not assess extrahepatic iron deposition. The parents of two children who died refused permission for a postmortem examination, so assessment of extrahepatic iron deposits was not possible (patients 2 and 5).

Patients 1-3 presented before 1994 and did not receive antioxidant treatment. Patient 1 died from multiorgan failure, and patients 2 and 3 underwent transplantation. Patient 3 was transplanted on day 13 of life and remains well with a follow up of 8 years. Patient 2 died from neurological damage after a successful transplant on day 45.

Patients 4-8 presented after 1994, all of whom received antioxidant treatment. Two infants died. Patient 5 presented on the first day of life and was treated immediately; patient 4 started antioxidants at 20 days after initial presentation. Both had multiorgan failure and were not listed for transplantation; they died within 48 hours of starting antioxidant treatment. Patient 6 had a partial response and survived for 37 days, when she underwent a liver transplantation. Unfortunately primary graft failure secondary to hepatic artery thrombosis occurred, which was complicated by neurological dysfunction so that retransplantation was contraindicated.

Two infants responded fully to antioxidant treatment (patients 7 and 8; table 3). Patient 7 had an affected sibling who had undergone successful liver transplantation at day 13 of life. Their mother had anti-Ro and anti-La antibodies and the diagnosis in the second sibling was suspected antenatally because he developed incomplete heart block in utero which is associated with both anti-Ro and anti-La antibodies. A fetal MRI to detect iron overload was attempted but was technically unsuccessful. The diagnosis was confirmed by a high cord ferritin concentration $(2093 \mu \mathrm{g} / \mathrm{l})$ and diagnostic liver histology performed on day 3 of life, when his coagulation had been partially corrected with medical treatment. Antioxidants were started on the first day of life. His ferritin concentration peaked at day $5(4193 \mu \mathrm{g} / \mathrm{l})$ and fell to $1557 \mu \mathrm{g} / \mathrm{l}$ by day 12 . Liver function improved after two days of antioxidant treatment.

Patient 8 presented at 3 days of age and was started on antioxidant treatment on day 4 of life. An associated finding of Coxsackie viral meningitis was noted, but diagnosis of $\mathrm{NH}$ was confirmed by liver histology and supportive MRI findings suggesting increased pancreatic iron. In both infants, treatment was continued until the ferritin level fell below $500 \mu \mathrm{g} / \mathrm{l}$ (at 28 and 35 days respectively). Both patients remain well at follow up of 36 and 48 months respectively, with no recurrence of iron overload.

In comparing the responses of the five children who received antioxidant treatment, it was clear that the two children who responded had lower ferritin levels and prothrombin times and started treatment earlier than nonresponders (table 3 ).

Table 2 Clinical features of patients with neonatal haemochromatosis

\begin{tabular}{|c|c|c|c|c|c|c|c|c|}
\hline & \multicolumn{8}{|l|}{ Patient } \\
\hline & 1 & 2 & 3 & 4 & 5 & 6 & 7 & 8 \\
\hline Gestational age (weeks) & 40 & 40 & 40 & 40 & 35 & 36 & 40 & 2.7 \\
\hline Birth weight $(\mathrm{kg})$ & 2.72 & 3.2 & 3.5 & 3.52 & 2.78 & 2.9 & 3.2 & 3.5 \\
\hline Age at presentation (days) & 31 & 30 & 1 & 4 & 1 & 16 & 1 & 3 \\
\hline Associated features & Consanguinity & - & $\begin{array}{l}\text { Maternal } \\
\text { anti-Ro anti-La, } \\
\text { affected } \\
\text { sibling }\end{array}$ & $\begin{array}{l}\text { E coli } \\
\text { septicaemia }\end{array}$ & $\begin{array}{l}\text { Consanguinity } \\
-2 \text { previous } \\
\text { perinatal } \\
\text { deaths }\end{array}$ & - & $\begin{array}{l}\text { Maternal } \\
\text { anti-Ro anti-La, } \\
\text { affected } \\
\text { sibling }\end{array}$ & $\begin{array}{l}\text { Coxsackie B } \\
\text { meningitis }\end{array}$ \\
\hline Ferritin ( $\mu \mathrm{g} / \mathrm{l})$ & 40000 & 4180 & 15000 & 7690 & 10000 & 2000 & 2093 & 1600 \\
\hline $\begin{array}{l}\text { Age started antioxidants } \\
\text { (days) }\end{array}$ & - & - & - & 23 & 1 & 18 & 1 & 4 \\
\hline $\begin{array}{l}\text { Age at liver transplant } \\
\text { (days) }\end{array}$ & - & 45 & 13 & - & & 37 & - & - \\
\hline Outcome & $\begin{array}{l}\text { Died from } \\
\text { MOF }\end{array}$ & $\begin{array}{l}\text { Died CNS } \\
\text { complications }\end{array}$ & Alive and well & $\begin{array}{l}\text { Died from } \\
\text { MOF }\end{array}$ & $\begin{array}{l}\text { Died day } 2 \\
\text { from MOF }\end{array}$ & $\begin{array}{l}\text { Died from } \\
\text { graft failure }\end{array}$ & $\begin{array}{l}\text { Responded to } \\
\text { antioxidants, } \\
\text { alive and well }\end{array}$ & $\begin{array}{l}\text { Responded to } \\
\text { antioxidants, } \\
\text { alive and well }\end{array}$ \\
\hline Post mortem & $\begin{array}{l}\text { Siderosis in } \\
\text { liver. Iron } \\
\text { stores not } \\
\text { examined in } \\
\text { other organs }\end{array}$ & Refused & - & $\begin{array}{l}\text { Grade } 4 \\
\text { siderosis in } \\
\text { liver. Iron } \\
\text { stores not } \\
\text { examined in } \\
\text { other organs }\end{array}$ & Refused & $\begin{array}{l}\text { Grade } 4 \\
\text { siderosis in } \\
\text { liver. Iron } \\
\text { stores not } \\
\text { examined in } \\
\text { other organs }\end{array}$ & - & - \\
\hline
\end{tabular}

The normal range for ferritin is $110-503 \mu \mathrm{g} / \mathrm{l}$.

MOF, Multiorgan failure; CNS, central nervous system. 
Table 3 Comparison of outcome with or without antioxidant treatment

\begin{tabular}{llllll}
\hline & \multicolumn{2}{l}{ No antioxidant treatment $(n=3)$} & Antioxidant treatment $(n=5)$ \\
\cline { 2 - 3 } & Died $(n=2)$ & $\begin{array}{c}\text { Transplanted, } \\
\text { alive }(n=1)\end{array}$ & & Died $(n=3)$ & Survived $(n=2)$ \\
\hline Age at presentation (days) & 30 & 1 & 7 & 2 \\
Age started antioxidants (days) & - & - & 14 & 2 \\
Mean ferritin concentration $(\mu \mathrm{g} / \mathrm{l})$ & 22090 & 15000 & 6663 & 1871 \\
Mean prothrombin time $(\mathrm{s})$ & 51 & 55 & 63 & 31.5 \\
\hline
\end{tabular}

\section{DISCUSSION}

$\mathrm{NH}$ is a rare condition, with published articles consisting mostly of isolated case reports or small series. There is a high mortality despite treatment. The clinical presentation is with acute liver failure at birth or within the early neonatal period. The diagnosis is based on the clinical features of acute liver failure, raised serum ferritin levels, hepatic histology showing increased iron stores sparing the reticuloendothelial system, and evidence of extrahepatic siderosis. ${ }^{1}$ It is not always possible to make the diagnosis before death or liver transplantation because of the difficulties in confirming liver histology in infants with abnormal coagulation. Recent data ${ }^{12}$ indicate that increased ferritin levels alone are insufficient for diagnosis, as ferritin is an acute phase reactant and may be increased in infants with liver failure from other causes. Alternative serum markers that may be more helpful include serum concentrations of transferrin and iron and percentage iron saturation of transferrin, ${ }^{1}$ and ferrritin should no longer be used as a marker for this disease. Likewise, it may be difficult to show extrahepatic siderosis, although lip biopsy may reveal iron in salivary glands, ${ }^{13}$ and MRI imaging may detect pancreatic iron deposits. ${ }^{14}{ }^{15}$ This difficulty in diagnosis is reflected both in the literature ${ }^{8-10}$ and in this historical study.

Both disorders of bile acids ${ }^{6716}$ and mitochondrial disorders ${ }^{17-19}$ have been described in association with acute liver failure, raised ferritin levels, and increased intrahepatic iron stores. It is therefore important to investigate for both of these disorders. In this series, mitochondrial disorders were excluded in all patients, and from 1994 disorders of bile acids, in five.

Treatment of this fatal disorder has focused on supportive treatment for acute liver failure and liver transplantation, which may be successful in some cases, ${ }^{89}$ and more recently on the use of antioxidant treatment. ${ }^{11}$ In this series, three children underwent liver transplantation, which was only successful in one patient. This was related to the development of multiorgan failure in the other two infants and the technical difficulties arising in such ill patients. The survival from liver transplantation has historically been poor, ${ }^{8-10}$ with only one previous report in the literature documenting long term survival after liver transplantation in two of three infants. ${ }^{8}$ These results indicate that, to date, liver transplantation for this condition is not as effective as for other indication ${ }^{11}{ }^{20}$ and cannot be considered optimal treatment in all cases.

In this series, antioxidant treatment improved outcome in two children, but these children had less severe disease and their antioxidant treatment was started earlier than in those who did not survive. The treatment effectively normalised the ferritin and reduced stored iron in the liver. A third child showed a partial response, with some clinical improvement allowing survival to transplant at day 37 . In none of the three cases has iron overload recurred, which is an unusual feature of this illness.

In the largest reported series of $\mathrm{NH}$, overall survival was $24 \%$, without improvement in outcome with antioxidant treatment. These authors found that there was a partial response with improved coagulation in one of eight patients on antioxidant treatment, but death or transplantation was not prevented in any of the patients. However, four of the patients were not diagnosed until after 1 month of age and consequently did not start antioxidant treatment until very late, which may have adversely affected the outcome. ${ }^{21}$

There have also been isolated reports of spontaneous recovery from $\mathrm{NH}$ in the literature, ${ }^{3122}$ and it is possible that the two patients in this study who responded to antioxidant treatment and who had a milder phenotype may have survived without this treatment. However, we feel that this is unlikely given the clinical presentation, the confirmatory liver histology, and the fact that an older sibling of one of the infants with a similar phenotype required liver transplantation.

In conclusion, the treatment of infants with $\mathrm{NH}$ remains controversial, and as intimated here, the timing of medical intervention is crucial. Progress in management of this disorder is difficult to assess prospectively as numbers of patients are small. However, survivors were referred early, and, since the introduction of antioxidant treatment, two patients required only medical management as opposed to the one survivor before the introduction of this treatment who required transplantation. We strongly recommend that all patients presenting with acute liver failure in the neonatal period should be started on an antioxidant cocktail while the diagnosis is being confirmed, allowing the earliest possible treatment. If there is no response to treatment within 48-72 hours (table 4), the infant should be listed early for liver transplantation, which should also be considered early in those with a more severe phenotype whose liver function is liable to deteriorate rapidly.

\section{Authors' affiliations}

D M Flynn, N Mohan, P McKiernan, S Beath, J Buckels, D Mayer,

D A Kelly, Liver Unit, Birmingham Children's Hospital, Steelhouse Lane, Birmingham B4 6NH, UK

Table 4 Poor prognostic factors in neonatal haemochromatosis and criteria for early listing for transplantation

\begin{tabular}{lll}
\hline $\begin{array}{l}\text { Persistently raised bilirubin } \\
\text { Persistently prolonged coagulation }\end{array}$ & $>200 \mathrm{mg} / \mathrm{I}$ & Normal range $<24$ \\
$\begin{array}{l}\text { Development of encephalopathy } \\
\begin{array}{l}\text { Persistent hypoglycaemia } \\
\text { Persistently raised ferritin }\end{array}\end{array}$ & $>$ grade 2 & Normal range 11-15 s \\
\hline
\end{tabular}

PT, Prothrombin time. 


\section{REFERENCES}

1 Murray KF, Kowdley KV. Neonatal hemochromatosis. Pediatrics 2001;108:960-4.

2 Kelly AL, Lunt PW, Rodrigues F, et al. Classification and genetic features of neonatal haemochromatosis: a study of 27 affected pedigrees and molecular analysis of genes implicated in iron metabolism. J Med Genet 2001;38:599-610.

3 Colletti RB, Clemmons JJ. Familial neonatal hemochromatosis with survival. J Pediatr Gastroenterol Nutr 1988;7:39-45.

4 Laxer RM, Roberts EA, Gross KR, et al. Liver disease in neonatal lupus erythematosus. J Pediatr 1990;1 16:238-42.

5 Schoenlebe J, Buyon JP, Zitelli BJ, et al. Neonatal hemochromatosis associated with maternal autoantibodies against Ro/SS-A and La/SS-B ribonucleoproteins. American Journal of Diseases in Children 1993; 147:1072-5

6 Siafakas CG, Jonas MM, Perez-Atayde AR. Abnormal bile acid metabolism and neonatal hemochromatosis: a subset with poor prognosis. J Pediatr Gastroenterol Nutr 1997:25:321-6.

7 Shneider BL, Setchell KD, Whitington PF, et al. Delta 4-3-oxosteroid 5 beta-reductase deficiency causing neonatal liver failure and hemochromatosis. J Pediatr 1994;124:234-8.

8 Lund DP, Lillehei CW, Kevy S, et al. Liver transplantation in newborn liver failure: treatment for neonatal hemochromatosis. Transplant Proc 1993;25:1068-71.

9 Muiesan P, Rela M, Kane P, et al. Liver transplantation for neonatal haemochromatosis. Arch Dis Child Fetal Neonatal Ed 1995;73:F17880.

10 Sigurdsson L, Reyes J, Kocoshis SA, et al. Neonatal hemochromatosis: outcomes of pharmacologic and surgical therapies. J Pediatr Gastroenterol Nutr 1998;26:85-9.

11 Shamieh I, Kibort PK, Suchy FJ, et al. Antioxidant therapy for neonatal iron storage disease (NISD) [abstract]. Pediatr Res 1993;33:109A.
12 Lee WS, McKiernan PJ, Kelly DA. Serum ferritin level in neonatal fulminant liver failure [letter]. Arch Dis Child Fetal Neonatal Ed 2001;85:F226

13 Knisely AS, O'Shea PA, Stocks JF, et al. Oropharyngeal and upper respiratory tract mucosal-gland siderosis in neonatal hemochromatosis: an approach to biopsy diagnosis. J Pediatr 1988:113:871-4.

14 Hayes AM, Jaramillo D, Levy HL, et al. Neonatal hemochromatosis: diagnosis with MR imaging. AJR Am J Roentgenol 1992;159:623-5.

15 Marti-Bonmati L, Baamonde A, Poyatos CR, et al. Prenatal diagnosis of idiopathic neonatal hemochromatosis with MRI. Abdom Imaging 1994; 19:55-6.

16 Setchell KD Schwarz M, O'Connell NC, et al. Identification of a new inborn error in bile acid synthesis: mutation of the oxysterol 7alpha-hydroxylase gene causes severe neonatal liver disease. J Clin Invest 1998;102:1690-703

17 Goncalves I, Hermans D, Chretien D, et al. Mitochondrial respiratory chain defect: a new etiology for neonatal cholestasis and early liver insufficiency J Hepatol 1995:23:290-4.

18 Krahenbuhl S, Kleinle S, Henz S, et al. Microvesicular steatosis, hemosiderosis and rapid development of liver cirrhosis in a patient with Pearson's syndrome. J Hepatol 1999;31:550-5.

19 Edery P, Gerard B, Chretien D, et al. Liver cytochrome c oxidase deficiency in a case of neonatal-onset hepatic failure. Eur J Pediatr 1994;153:190-4.

20 Kelly DA. Current results and evolving indications for liver transplantation in children. J Pediatr Gastroenterol Nutr 1998;27:214-21.

21 Sigurdsson L, Reyes J, Kocoshis SA, et al. Neonatal hemochromatosis: outcomes of pharmacologic and surgical therapies. J Pediatr Gastroenterol Nutr 1998;26:85-9

22 Muller-Berghaus J, Knisely AS, Zaum R, et al. Neonatal haemochromatosis: report of a patient with favourable outcome. Eur J Pediatr 1997; 156:296-8.

\section{Archimedes}

In order to give the best care to patients and families, paediatricians need to integrate the highest quality scientific evidence with clinical expertise and the opinions of the family. Archimedes is a bimonthly section in Archives which seeks to assist practising clinicians by providing "evidence based" answers to common questions which are not at the forefront of research but are at the core of practice.

The format of Archimedes may be familiar. A description of the clinical setting is followed by a structured clinical question and a brief report of the search. The best evidence available to answer the question is provided as a summary table (which is electronically linked to more detailed appraisals). To pull the information together, a commentary follows. Finally, to make it all much more accessible, a box provides the clinical bottom line. This month the following topics have been published which may be of interest to neonatologists:

- Can traffic calming measures achieve the Children's Fund objective of reducing inequalities in child health?

- Should verrucas be covered while swimming?

- What is the normal range of blood glucose concentrations in healthy term newborns?

Previous Archimedes questions can be found in the issues of Archives published in the Fetal and Neonatal edition months since September 2001. Readers wishing to submit their own questions-with best evidence answers-are encouraged to read the Instructions for Authors at http://www.archdischild.com. 